\title{
O DIÁRIO-DE-OBRAS NO SISTEMA DE GÊNEROS DA ENGENHARIA CIVIL ${ }^{1}$
}

\section{THE CONSTRUCTION DIARY IN THE CIVIL ENGINEERING GENRE SYSTEM}

\author{
Solange Aparecida Faria Cardoso \\ solangejac@yahoo.com.br
}

UFU

\begin{abstract}
RESUMO: O objetivo deste trabalho é analisar parte de textos relativos a uma obra de Engenharia Civil, sob a ótica da linguagem como prática social, com ênfase no campo das práticas sociais no trabalho. As discussões realizadas por Bazerman (2006) quanto às noções de gênero discursivo, conjunto de gêneros, sistema de gêneros e sistema de atividades são a base para a análise. Nesta análise, foram consideradas as convenções para os procedimentos efetivados na construção civil no contexto brasileiro, encontradas em lei, e em um corpus de referência, qual seja, um Diário de Obras produzido durante a ampliação de área industrial, executada por uma construtora de Uberlândia-MG. Buscou-se identificar os sujeitos e seus papéis nos gêneros dos quais participam, evidenciando as atividades realizadas mediante textos escritos. Foi constatado que o Diário de Obras é um dos mecanismos textuais do complexo sistema de gêneros em que se constitui uma empresa da construção civil e funciona como um dos mecanismos que sustenta o caráter altamente especializado das atividades realizadas pelos representantes da Engenharia Civil.
\end{abstract}

PALAVRAS-CHAVE: sistema de atividades; sistema de gêneros; engenharia civil; diário-deobras.

ABSTRACT: The goal of this essay is to analyze part of texts related to a civil engineering enterprise, under the view of language as a social practice, and emphasizing the field of social practices at work environment. The discussions brought by Bazerman (2006) about notions on discoursive genre, genre group, genre system and activity system are the basis for that analysis. Conventions for civil building used in Brazilian context were used, as found on the law, and at a reference corpus, which was a Construction Diary composed during the improvement of an industrial area, carried on by a building enterprise from Uberlandia-MG. We intended to identify subjects and their roles on the genres in which they participate, enlightening the activities illustrated through written texts. It was observed that the Construction Diary is one of the textual mechanisms of the complex genre system in which a civil construction enterprise is formatted, and works as one of the tools that brings about the highly specialized nature of the activities carried on by Civil Engineering individuals.

KEY WORDS: activity system; genre system; civil engineering; construction diary.

\section{Introdução}

Ao longo do tempo, as atividades de construção civil mantiveram importância evidente na formação da sociedade moderna e contemporânea. Essas atividades não apenas forneceram soluções para questões humanas cruciais como a habitação, o conforto e o abrigo contra as intempéries em todos os sentidos, como também - e até por

\footnotetext{
${ }^{1}$ Agradecemos ao Prof. Dr. Luiz Carlos Travaglia (Mestrado e Doutorado em Estudos Linguísticos - UFU) por suas observações à primeira versão deste estudo.
} 
isso - influenciaram a cultura humana de modo geral e definitivo, sem se restringir a um mero espelho que reflete tais nuanças.

As contribuições e influências da Engenharia Civil são notáveis também em outras ciências dela dependentes ou a ela relativas, como a Geologia, a Geografia e a Arquitetura, e esse intercâmbio se dá essencialmente através da linguagem empregada pelos profissionais dessa área. Estas interrelações são, portanto, inegáveis objetos de estudo da linguística - e são de importância singular, tendo em vista que fundamentam a comunicação em uma área essencial à vida moderna.

Diante do citado panorama, o objetivo deste trabalho é a análise das atividades de gênero escrito singulares à construção civil e afins, do ponto de vista linguístico. Neste sentido, escolhemos um tipo de texto para análise mais detalhada: o Diário de Obras (doravante DO). A escolha desse tipo de texto se deve ao fato de, pela própria natureza deste trabalho, não dispormos de espaço para a análise de outros textos e também, pela importância do DO de, entre outras, não só ordenar as atividades diárias a serem desenvolvidas em uma construção civil, como também a de deixar registro documentado para possibilitar o desenvolvimento de outras atividades, no futuro, em uma mesma obra. De modo mais específico, sob a perspectiva dos gêneros linguísticos, avaliamos quais atividades de constituição de textos são desempenhadas, nesse tipo de texto, seus protagonistas e o modo de controle e organização, levando-se em conta a especialidade da área escolhida.

Neste sentido, a consulta a documentos de circulação interna em uma empresa de construção civil, aqui denominada $\mathrm{DT}^{2}$, forneceu-nos o material necessário a nosso entendimento e estudo acerca dos termos comumente empregados na área, e que dão a noção exata da mensagem a ser comunicada. O corpus é constituído por 97 formulários denominados Diário de Obras que foram numerados (de 01 a 97) para facilitar a análise dos textos. Os formulários constituem-se em DO da execução do projeto denominado "Casa de Força" e foram coletados, por empréstimo, em situação real, a partir de entrevistas com um profissional da área de uma empresa de construção civil da cidade de Uberlândia-MG. Para a referida análise, optamos por ater-nos somente a tipos de textos dos formulários, quais sejam: tempo (condições climáticas), número de mão de obra, ocorrências, aspectos sociais e serviços executados.

\footnotetext{
${ }^{2}$ No intuito de preservar o sigilo exigido por cláusula contratual, todos os dados informativos, como nomes e especificações, serão substituídos por outros fictícios.
} 
É importante ressaltar que as bases da linguística nos fornecem estímulo de sobejo para iniciar o estudo. Para Souza-e-Silva (2002, p. 63), a escolha de determinadas interações no trabalho como objeto de estudo traz a necessidade de "recorrer a noções advindas de outras disciplinas" (quais sejam, a Engenharia Civil e correlatas) e "fazer empréstimos diversificados no âmbito da própria disciplina".

Isto posto, vêm-nos à memória as palavras de Nouroudine (2002, p. 17), segundo o qual a linguagem "é ela própria trabalho". Para ele, a linguagem, em sua relação com o trabalho, pode identificar três espécies distintas: "linguagem sobre o trabalho" (linguagem que interpreta), "linguagem no trabalho" (linguagem circundante, constitutiva da situação) e "linguagem como trabalho" (linguagem que faz, constitutiva da atividade).

Outrossim, é possível postular, diante das interrelações entre a Engenharia Civil e as ciências correlatas, a impossibilidade de se desvincular a linguagem das atividades humanas. Segundo Brait (2002, p. 38), a noção de gêneros não existe "sem pensar na esfera de atividades específicas em que eles se constituem e atuam, aí implicadas as condições de produção, de circulação e de recepção". Em face disso, tornam-se cruciais investigações referentes a quem emite a mensagem, a partir de que local, e em que momento. As respostas a tais questões estabelecem o marco zero de investigações mais aprofundadas acerca do uso da língua em diversas atividades, especificamente na que pretendemos estudar, ou seja, o DO de uma obra de Engenharia.

O posicionamento linguístico conhecido como "gênero como ação social" (BAZERMAN, 2004; DEVITT, 1991; MILLER, 1984) denota o estudo de um gênero que cumpre funções determinadas, relaciona-se a participantes específicos, em locais e tempo também peculiares. A linguagem escrita é vista como pretendendo atingir um certo objetivo, em uma determinada ocasião ou evento. Assim, a documentação relativa a uma obra de engenharia - nosso objeto de estudo - pode ser entendida como um sistema de gêneros.

\section{DIÁRIO DE OBRAS como parte do sistema de gêneros}

\subsection{Revisitando a teoria: textos como organizadores de atividades}

Para Souza-e-Silva (2002, p. 61), a atividade de linguagem e a atividade de trabalho estão estreitamente ligadas; ambas transformam o meio social e permitem trocas e negociações entre os seres humanos. Nesta perspectiva dialógica, já proposta por Bakhtin ([1929]2003), os seres humanos, em situação de comunicação verbal ativa, selecionam as palavras segundo as especificidades do gênero de que participam; 
determinados tipos de enunciados são gerados por uma determinada função (científica, técnica, oficial, cotidiana, etc.) e por determinadas condições de comunicação, específicas de cada campo.

Assim, pesquisadores como Bazerman (2006) têm objetivado investigar os contextos social, cultural e institucional dos gêneros, além de descrever suas formas lexicogramaticais e padrões retóricos, a fim de verificar como usuários especialistas utilizam gêneros para propósitos sociais. Em nossas pesquisas, pudemos verificar a aplicação dessas bases teóricas em outras áreas do conhecimento humano. Um exemplo dessa aplicação é o estudo realizado por C. Fuzer (2008) no que se refere à organização de textos como sistema de gêneros na área de Processo Penal no Brasil, e do qual este trabalho toma emprestado alguns fundamentos.

Nesse sentido, sustentados pela teoria dos filósofos John Austin e John Searle, o texto é definido sob o ponto de vista de enunciado, que incorpora "atos de fala". O ato de fala é o resultado de palavras ditas em tempo, em circunstâncias apropriadas e pela pessoa adequada. Segundo Bazerman (2006, p. 29), "uma maneira de coordenar melhor nossos atos de fala uns com os outros é agir de modo típico, modos facilmente reconhecíveis como realizadores de determinados atos em determinadas circunstâncias".

Essas formas de comunicação, que seguem padrões razoavelmente estáveis com os quais as pessoas de um determinado grupo social estão familiarizadas, surgem como gêneros, vistos como respostas a situações sociais recorrentes. Certos gêneros tipificam as atividades de determinados grupos sociais. 'Tipificação' é o termo usado por Bazerman (2006, p. 29) para designar o "processo em direção a formas de enunciados padronizados, que reconhecidamente realizam certas ações em determinadas circunstâncias, e a uma compreensão padronizada de determinadas situações". Gêneros são, portanto, "parte do modo como os seres humanos dão forma às atividades sociais" (BAZERMAN, 2006, p. 31).

Bazerman (2006) define como conjunto de gêneros a coleção de textos produzidos por uma pessoa, por ocasião de execução de uma atividade. Esse conjunto corresponde a todos os gêneros utilizados por um agente para exercer seu(s) papel(éis) no grupo de que participa. A identificação de um conjunto de gêneros possibilita arrolarem-se as atividades típicas de determinado profissional, as quais são necessárias para a realização do trabalho com competência.

Os diversos conjuntos de gêneros utilizados por pessoas que trabalham de modo organizado, considerando-se as relações padronizadas que se estabelecem na produção, 
circulação e uso dos textos, fazem parte de um sistema de gêneros (BAZERMAN, 2006). No sistema, um gênero segue um outro gênero numa sequência regular, em uma direção comunicativa peculiar de um grupo de pessoas. Num sistema de gêneros, os conjuntos de gêneros estão ligados e circulam em sequências e padrões temporais previsíveis.

Fazur e Barros (2008, p. 47) afirmam que "o circuito se completa com o sistema de atividades típicas de uma determinada instituição. A definição do sistema de gêneros, de que as pessoas participam, possibilita ao analista identificar uma estrutura que organiza o trabalho, a atenção e as realizações dessas pessoas no exercício de suas atividades."

Seguindo a perspectiva de Bazerman (2006), quando se considera o sistema de atividades junto com o sistema de gêneros, tem-se em foco o que as pessoas fazem e como os textos ajudam a fazê-lo. É nesse sentido que buscamos analisar um DO produzido durante a execução de uma obra pela empresa de construção civil, a DT.

\subsection{Contextualização: a empresa pesquisada}

Para melhor compreender o tema "Construção Civil", optamos por obter de Palacios (1995), teórico do assunto, breves considerações relevantes e que nos auxiliam na tarefa de contextualizar o tema e a empresa.

Para Palacios (1995), a construção civil é uma atividade industrial altamente fragmentada, que envolve uma enorme diversidade de interventores. Esta característica justifica inteiramente a formulação e desenvolvimento de um planejamento, interligado a um controle gerencial que permita a execução de projetos com maior economia, melhor qualidade, segurança e menores prazos.

No atual cenário da indústria da construção, cada vez mais competitivo, o planejamento, o controle e a ordenação da complexidade dos processos constituem as características das empresas de sucesso. Assim, acompanhamento e controle podem ser transformados em ferramentas fundamentais no processo de competitividade, e agem de forma a auxiliar a empresa a se tornar bem-sucedida. O organograma apresentado pela empresa pesquisada demonstra que a diretoria decide o que fazer, quem deve fazer, quando, onde e, muitas vezes, como fazer. Para melhor compreensão, vejamos: 


\section{ORGANOGRAMA}

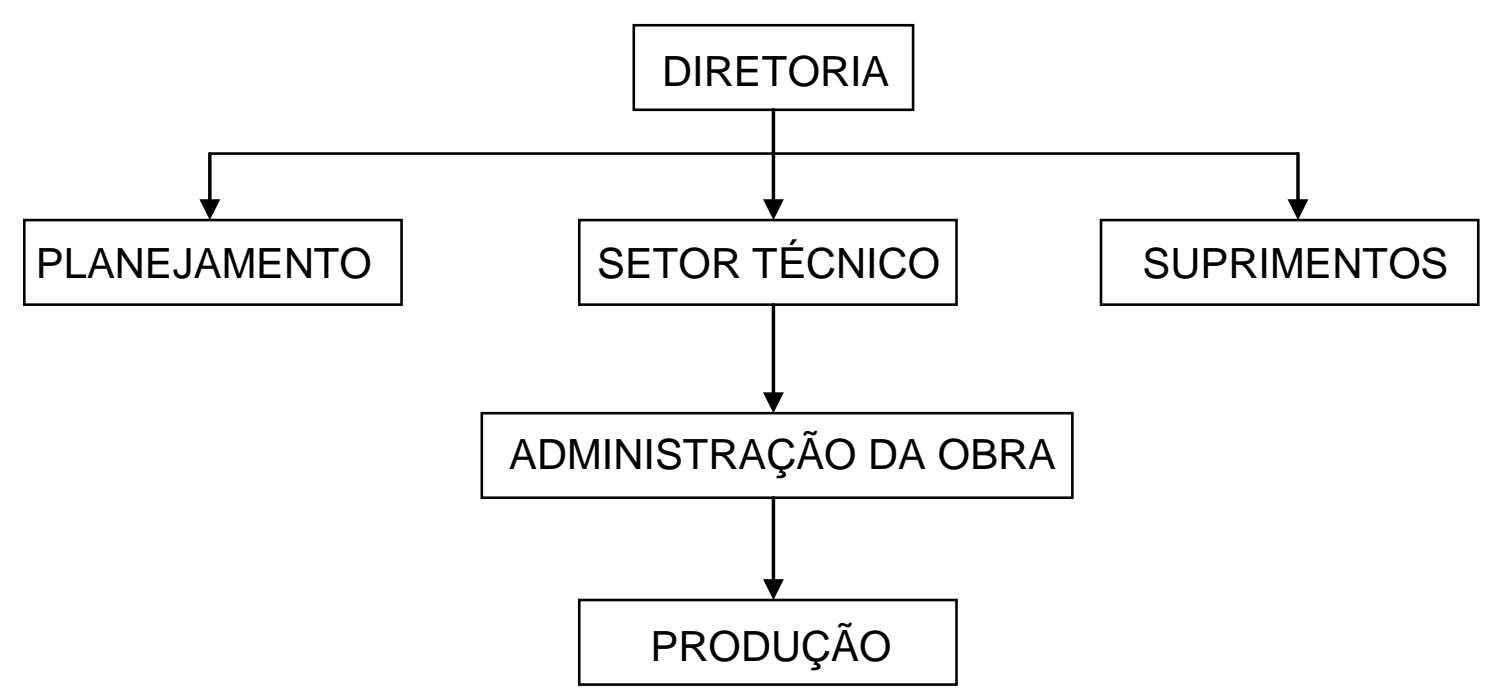

No que se refere à teoria basilar dessa pesquisa, a empresa de construção civil organiza suas ações por meio do que Bazerman (2006) identifica como sistema de gêneros. Além de toda a documentação exigida pelas instâncias legais na instituição da empresa, suas ações serão ordenadas por meio de conjuntos de gêneros. A seguir, apresentamos uma breve análise de como a Empresa DT de Construção Civil organiza suas ações por meio de textos.

\section{Registros escritos do DO: uma análise}

\subsection{O Formulário}

No contexto atual, é possível percebermos que as diferentes empresas, independentemente do campo de atuação, são constituídas por agentes, ou seja, especialistas nas áreas em questão. Estes realizam ações tipificadas que são textualizadas em gêneros apropriados para sua efetivação no meio escrito. Assim, o agente é o critério para a composição de um conjunto de gêneros.

Em se tratando da Engenharia Civil, autorizado o início das obras, um formulário nomeado DIÁRIO DE OBRAS é preenchido a cada jornada de trabalho. O Novo Dicionário Aurélio (1986) bem define DO como um caderno que permanece no canteiro de obras e no qual o mestre-de-obras, os engenheiros e o arquiteto fiscal anotam as ocorrências importantes de cada jornada de trabalho.

Importante ressaltar o fato de que, sendo a construção civil uma atividade responsável por envolver outras ciências, como a Geologia e a Geografia, verificamos, 
por meio da análise do DO, o intercâmbio que se dá entre os profissionais dessas diferentes áreas, essencialmente por meio de textos. Ou seja, por meio do DO, sabemos da existência de textos redigidos por outros especialistas que também atuam na construção de uma nova edificação. Assim, o DO, como parte do sistema de gêneros na construção civil, agrega ou gera outros gêneros, dentro de um fluxo comunicativo típico de um grupo de pessoas.

Durante a nossa pesquisa, verificamos, mesmo sem nos determos na descrição detalhada das ações desenvolvidas pelos membros do organograma, que, já instalada no ramo da indústria de construção civil, a DT, empresa por nós analisada, organiza suas ações por meio de uma sequência de atos, concatenados na forma apresentada a seguir.

No primeiro momento, há a elaboração e apresentação de um dossiê aos clientes. Então, recebida uma proposta de trabalho - no caso desta pesquisa, a ampliação em fábrica de ração situada em Uberlândia-MG e execução do Projeto Casa de Força -, a DT elabora e apresenta ao cliente a proposta técnica. ${ }^{3}$

Além da proposta técnica, é organizada uma pasta com um conjunto de textos, nomeada Estudos e Levantamentos Geológico-Geotécnicos. Nesses estudos são apresentadas, em forma de relatórios, investigações geofísicas para confirmar e identificar importantes condicionantes geológico-geotécnicas e ambientais, que indicarão, ou não, a necessidade de novos estudos de arranjos alternativos nos projetos de construção. Por meio desses estudos, e conforme a natureza e dimensões da nova edificação, são elaborados programas de investigações para a caracterização dos materiais naturais que poderão ser utilizados na construção.

Como já afirmamos acima, o planejamento e a programação das ações em construção civil constituem fatores de sucesso para a empresa executora. Sendo assim, as ações da DT são planejadas e acompanhadas diariamente.

\subsection{Estrutura composicional do DO}

Entendendo que o planejamento da programação da obra implica, inicialmente, numa previsão das atividades a serem realizadas, dos recursos necessários, dos custos estimados, dos prazos e de tantos outros elementos importantes para a execução e para

\footnotetext{
${ }^{3}$ Saliente-se que todos os documentos analisados integram o acervo do arquivo morto da construtora pesquisada. É permitida tão-somente a análise de tais textos, e vedada eventual publicação.
} 
o acompanhamento, os registros feitos no DO assumem importante papel na execução de obra de construção civil.

O DO destina-se ao registro mais ou menos detalhado dos serviços executados diariamente no canteiro de obras, assim, a estrutura composicional desse documento deve conter: (Anexo - formulário em branco)

a) A identificação: obra, código, empreiteiro, dias (corridos, úteis, obra), engenheiro, mestre de obras e data da emissão.

b) O registro das condições do tempo. As condições do tempo são registradas não por meio de texto corrido, mas em forma de múltipla escolha: quadrinhos onde são marcadas com $X$ as condições do tempo pela manhã e tarde (BOM, CHUVA FRACA, CHUVA FORTE).

c) O número de equipamento (betoneira, girica, maquita, vibrador, carrinho, furadeira, serra circular, compactador, mangote) e mão-de-obra (encarregado de pedreiro, pedreiros, meio oficial pedreiro, serventes, encarregado de carpinteiro, carpinteiros, meio oficial carpinteiro, encarregado eletricista, eletricista, meio oficial eletricista, encanador, meio oficial encanador, armadores, meio oficial armador, pintores, apontador, vicias, marceneiros) específicos é indicado em quadrinhos onde é registrada, em dois dígitos, a quantidade de cada um utilizado nas jornadas de trabalho. No caso da mão-de-obra, é indicado o número de funcionários presentes e o número dos ausentes.

d) Dois espaços são reservados para o registro, em forma de texto, dos serviços executados (10 linhas), visitas, ocorrências, solicitantes e observações (5 linhas).

e) No final do formulário, há espaço reservado para a assinatura dos enunciadores do texto (apontador, mestre-de-obras) e visto do engenheiro residente e da gerência de obras.

\subsection{Condições de produção}

Em consonância com a definição de Ferreira (1986), na proposta técnica da DT, no item CONTROLE TECNOLÓGICO da Proposta Técnica, lemos que "far-se-á o registro em diário de obra ${ }^{4}$ de todas as ocorrências à medida que forem desenvolvidos os serviços, de forma a utilizar e viabilizar o bom desempenho das etapas de trabalho". No caso específico da empresa pesquisada, o DO é constituído por formulário preenchido, diariamente, em duas vias, sendo uma cópia em carbono, destinada ao arquivo morto da

\footnotetext{
${ }^{4}$ Grifo nosso.
} 
empresa, ao final da obra. A outra cópia é destacada do bloco e pode ter vários destinatários, conforme os apontamentos nela feitos: o mestre-de-obras, os operários (pedreiros), os chefes específicos de atividades terceirizadas (subempreiteiros), a empresa construtora e, também, os agentes assim constituídos pelos proprietários da edificação em construção, para efeito de orientação e/ou fiscalização. A pluralidade advinda do fato de o DO possuir vários destinatários pode ser observada também quando se analisa o emissor do texto.

O local de produção de um DO, como já afirmamos, é o canteiro de obras, e quem o redige é o apontador ${ }^{5}$. No entanto, todas as anotações são feitas a partir de outras referidas pelo Engenheiro Residente. Este profissional acompanha, no canteiro de obras, todas as ações desenvolvidas pelos profissionais. Durante este acompanhamento, ele anota - muitas vezes em pequenos pedaços de papel e/ou pequenos blocos - as ações já desenvolvidas ou em desenvolvimento, procedimentos e/ou condutas a serem adotadas, informações, ocorrências, dificuldades e solicitações. No início ou final de cada jornada de trabalho, há uma reunião entre o Engenheiro Residente, mestre-de-obras e o apontador. Neste momento, o DO é preenchido pelo apontador, e assinado pelo mestre-de-obras, pelo Engenheiro Residente e pela gerência de obras.

\subsection{Análise dos registros}

$\mathrm{Na}$ análise dos 97 formulários $^{6}$, destacamos alguns aspectos que certamente demonstram a importância do DO durante a execução de um projeto no imbricado sistema de gêneros numa empresa de construção civil.

Inicialmente, chamaram-nos a atenção os registros relacionados às condições climáticas que interferem nas ações dos agentes no canteiro de obras. No formulário 03, podemos perceber que o apontador assinalou chuva forte nos períodos manhã e tarde e, consequentemente, no espaço onde são descritas as ocorrências lemos: "Devido as fortes chuvas estamos impossibilitados de dar início as obras pois o local está encharcado de água...".

Outro exemplo em relação ao mesmo item aparece no formulário 23. Há o registro "Chuva forte após as 14:00, dificultando os nossos serviços." No formulário 24, lemos no

\footnotetext{
${ }^{5} \mathrm{O}$ apontador é um auxiliar administrativo atuante no canteiro de obras. Além do preenchimento do DO, ele tem a responsabilidade de fazer orçamentos e requisições de material, estabelece contato com outros engenheiros, confere os cartões de ponto e realiza outras atividades de apoio ao prosseguimento da obra.

${ }^{6}$ As transcrições a seguir obedecem fielmente às anotações do DO, respeitando inclusive as incorreções gramaticais que porventura se façam presentes.
} 
item serviços executados: "Devido as fortes chuvas de ontem, tivemos de bater a água toda que armazenou nos blocos, vigas baldrames escavados. Estamos tendo dificuldade de chegar com caminhão brasmix para concretar as 7 estacas restantes do gerador. Chuva forte a partir das 15:00, dificultando os nossos trabalhos, pois, o serviço é escavação dos blocos e vigas baldrame."

Por meio das transcrições feitas acima, percebemos que o registro das "condições do tempo" é um dos determinantes das ações. Além disso, esse registro é importante, principalmente no sentido de proteger a empresa contra possíveis multas, pelo não cumprimento de prazos estabelecidos em contratos. Mesmo assim, não impedem que se registre que o cliente "(...) solicitou mais rapidez na obra, estamos empenhados em atendê-los, conforme o tempo possa permitir" (formulário 15); "(..) solicitou mais rapidez na cobertura do (...), estamos nos empenhando para deixar coberto hoje" (formulário 66).

Interessante notar que não só as condições climáticas podem afetar o bom andamento na execução de um projeto de construção civil, mas também problemas de ordem mecânica e sociais. No que diz respeito a "problemas de ordem mecânica", no DO lemos "Estamos sem poder trabalhar c/ a serra circular para confecção de formas. Não tem energia até 12:00". "Caminhão perfuratriz da Popular com problemas, parada as escavações". "Solicitei ao Eng. Antônio - Popular - disponibilidade de outro caminhão para ajudar nas perfurações das estacas, disse que não tem, e o caminhão que está com problemas mecânico, a peça chegaria somente à tarde, estamos aguardando" (formulário $16,14,15)$.

Quanto a "aspectos sociais", verificamos que fatos envolvendo as questões de transporte coletivo, entre outros, também podem afetar as atividades desenvolvidas no canteiro de obras. Assim, é importante o registro feito no formulário 78, no item "ocorrências", "Estou com dificuldade em relação a funcionários devido a greve do transporte coletivo em Uberlândia." Percebemos que houve transtornos nas jornadas de trabalho. Se compararmos o número de profissionais atuando no canteiro de obras nos formulários 77 e 78, perceberemos um alto índice de faltas. Verificamos que no dia 25/04/08, estão registrados 11 pedreiros e 17 serventes; já no dia 28/04/08, foram registrados apenas 06 pedreiros e 07 serventes presentes.

O espaço "Serviços Executados" é utilizado também para apontar outras ocorrências importantes, como mudanças de projeto cuja necessidade se identificou à medida que se realizava a construção e os estudos geotécnicos e testes de precisão das estruturas. Estes registros são de importância singular para a orientação de futuras 
intervenções, uma vez que servem como relato fiel do próprio histórico da obra. Assim, no formulário 01 está registrado "Recebi projeto casa força no CP-1517-6101...". Já no formulário 02, lemos "Marcos (...) disse que será alterado os projetos casa de força, inclusive locação. Estamos aguardando definição."

No formulário 03, encontra-se o seguinte registro: "Recebi projeto Casa de força Fundação - C-1517-6101 Revisão com alterações de cargas de alguns pilares e com ferragens de estacas. Foi conversado com Eng Beto-esc. Técn. A. N. Ramos S/S LTDA sobre a profundidade das estacas, e ficou definido que seria com 14 metros solicito documentos de tal fato por escrito." Neste relato, percebemos a troca de textos (informações) que favorecem o bom desenvolvimento das ações. Nesse contexto, foi apresentado o relatório de sondagem geológica redigido pelo topógrafo em que se definia a profundidade das estacas em consonância com os estudos do terreno.

Outro aspecto relevante diz respeito à previsão e utilização de equipamentos e mão-de-obra. Se feita com precisão no DO, possibilita a execução de diferentes obras com o mesmo conjunto (equipamento, mão-de-obra). Assim, por meio da frequente remissão aos dados contidos no DO, a empresa viabiliza a manutenção do grupo profissional e a utilização de equipamentos, mantendo o maior grau possível de eficiência não apenas no canteiro de obras, mas também em outras áreas da empresa. É o que pudemos constatar em vários formulários do DO, no item "serviços executados", ações desenvolvidas fora do canteiro de obras. Um exemplo é o registro do formulário 16, em que podemos ler, "Estamos cortando/dobrando ferragem dos blocos/vigas baldrames e pilares, dos projetos que recebi ontem (11/02) no almoxarifado da DT".

\subsection{Perspectiva textual do DO}

$\mathrm{Na}$ perspectiva dos estudos tipológicos desenvolvidos por Travaglia (2003), é possível considerarmos o DO um gênero do tipo narrativo da espécie "não-história". Isto porque, ao observarmos a estrutura textual do DO, a mesma é próxima à de uma ata guardando, evidentemente, as constituições específicas.

Segundo Travaglia (2003), na narração, o produtor se coloca na perspectiva do fazer ou acontecer inserido no tempo. O que quer é contar o que aconteceu, dizer os fatos, os acontecimentos. Portanto, o tipo de informação necessária são os fatos ou acontecimentos, constituindo episódios, ordenados no tempo do mundo real.

Para exemplificar, transcrevemos o texto do formulário 94: "Não foi possível colocar forma do vigamento de respaldo e pilares, porque, desmontaram os andaimes interno da 
sala do gerador e turbina sem o nosso consentimento. Com isto, causando transtorno no andamento de nossos serviços, além de que, temos que montar todo o andaime novamente. (Houve danificação das formas que já se encontravam no andaime)."

Assim, podemos observar que o produtor adota a perspectiva do fazer ou acontecer inserido num tempo real. Os registros feitos no DO - os episódios -, não só nesse como também em outros formulários já transcritos, estão lado a lado no texto, mas não se encadeiam em direção a um resultado, ou seja, não há sucessão e sim correlação entre os fatos.

\subsection{Estilo da linguagem}

Em relação ao estilo da linguagem, em sua maioria, no geral, os textos constituemse em frases com verbos nos tempos compostos. Assim, no formulário 05 está registrado "Estamos executando projeto de armação de estacas...". Nos formulários 14, 16, 18 e 53, lemos "Estamos escovando estacas, confeccionando ferragens...". "Estamos confeccionando formas dos pilares/vigas estruturais... Estamos fabricando toda estrutura metálica...". "Estrutura metálica já está sendo confeccionada (cobertura) Esquadrias metálicas estão sendo executada."

Outro aspecto interessante é que as orações utilizadas pelo apontador, por vezes, se iniciam com substantivos. "Colocação ferragem de vigas e laje preparação do fundo e paredes da base gerador" (registro formulário 36). "execução de alvenaria, chapisco e reboco" (formulário 54). "aplicação de selador na alvenaria e esmalte nas esquadrias metálicas. Limpeza geral. Montagem de andaimes interno a sala guarda e turbina" (formulário 75).

O exemplo dos formulários 2 e 4 nos mostra que são utilizados também verbos enunciativos: "Marcos (...) disse que será alterado os projetos casa de força, inclusive locação." "À tarde Ivanilson disse que, do jeito que está o terreno..."

Não cabe a este estudo investigar detidamente aspectos referentes à formulação textual do DO. Outros estudos podem ser realizados com o objetivo de melhor investigá-la e descrevê-la de maneira bem detalhada. Neste artigo, apenas para ampliar nossas observações, registramos os aspectos acima detectados quanto à formulação textual e estilo da linguagem do DO analisado.

Por meio da breve análise realizada acima, ainda que pouco detalhada, obtém-se a concepção de que uma empresa de construção civil, no desempenho de suas atividades, promove uma sequência de eventos em que muitos textos e diversos fatos sociais são 
produzidos. Esses fatos só existem porque pessoas os realizam por meio da criação de textos (BAZERNAM, 2006). A DT, intermediada por seus sujeitos - diretoria, engenheiros (residente, auxiliar, planejamento), mestre-de-obras e apontador - elabora textos. Estes, ordenando atividades, estabelecem sistemas organizacionais bem articulados, possibilitando o alcance de objetivos que, nesse caso, configuram-se na edificação do projeto Casa de Força de uma fábrica de ração em Uberlândia-MG.

\section{Considerações finais}

Em sua teoria, Bazerman sugere que, numa sequência de eventos, muitos textos e fatos sociais são produzidos. A finalidade desse artigo foi de, com base nestas idéias, contribuir para o processo de contextualização de atividades típicas do trabalho realizado no campo da construção civil. Pudemos verificar, em consonância com a teoria de Bazerman (2006), que um sistema de gêneros captura as sequências regulares com que um gênero segue outro, dentro de um fluxo comunicativo típico de um grupo de pessoas.

Como parte importante da vida social humana, a construção civil organiza suas ações por meio de conjunto de gêneros (dossiê, proposta técnica, Estudos e Levantamentos Geológico-Geotécnicos, relatórios de ensaios). Nessa pesquisa, defendemos que o DO se caracteriza como parte integrante do sistema de gêneros relativamente estável, porque possui estrutura composicional, contexto de produção, perspectiva textual, objetivos e funções com particularidades específicas. Defendemos, ainda, que o DO organiza as atividades da competência daqueles que atuam no canteiro de obras, desempenhando atividades típicas da construção civil. Todo o processo, que culmina com uma nova edificação - momento em que construtora e cliente assinam os termos de entrega, recebimento e aceite da obra objeto da proposta técnica -, é permeado por conjunto de gêneros que partem da administração e perpassam todos os outros setores, formando uma permanente rede de troca de textos (informações) que favorecem o bom desenvolvimento das ações.

No contexto analisado, entendemos que, especialmente nas obras em execução em áreas externas, as condições climáticas podem justificar atrasos na entrega da obra, sem que se configure a aplicação da multa contratual. Entretanto, não são apenas as condições climáticas a determinarem ações ou mudanças de ações. Questões outras, como uma greve no transporte coletivo que se configure como fato social, exercem também influência nas atividades a serem desenvolvidas no canteiro de obras. Assim, o 
DO é o registro de "fatos sociais que afetam as ações, direitos e deveres das pessoas" (BAZERMAN, 2006).

Portanto, a empresa de construção civil se organiza como um sistema de atividades, executadas por determinados agentes, com conhecimento especializado para cumprirem seus papéis no subuniverso social de que participam.

Ao analisar o DO de uma empresa de construção civil, melhor compreendemos que se nas escolas trabalhássemos as habilidades de escrita para a produção de conjunto de gêneros relacionados, estaríamos desenvolvendo um ensino mais contextualizado, que certamente contribuiria para melhores resultados. Para Bazerman (2006), não ensinamos gêneros; podemos, sim, desenvolver as habilidades dos diferentes registros em língua escrita, por meio do trabalho de como funciona os gêneros na sociedade.

Neste sentido, outras pesquisas devem ser desenvolvidas concentrando-se na construção do texto, nos sentidos produzidos no e pelo discurso, na caracterização formal e léxico-gramatical dos gêneros discursivos, dentre outras questões do âmbito linguístico.

\section{Referências}

BAKHTIN, M. Estética da criação verbal. São Paulo: Martins Fontes, 2003 [1929].

BAZERMAN, C. Gêneros textuais, tipificação e interação. Tradução e organização de Ângela Paiva Dionísio e Judith Chambliss Hoffnagel. São Paulo: Cortez, 2006.

BRAIT, B. Perspectiva dialógica, atividades discursivas, atividades humanas. In: SOUZAE-SILVA, M. C. P.; FAiTA, D. (Orgs.). Linguagem e trabalho: construção de objetos de análise no Brasil e na França. São Paulo: Cortez, 2002. p. 31-44.

DEVITT, A. Intertextuality in tax accouting. In: BAZERMAN, C.; PARADIS,

J. (Eds.). Textual dynamics of the professions. Madison: University of

Wisconsin Press, 1991. p. 336-357.

FUZER, Cristiane; BARROS de, Nina Célia. Processo penal como sistema de gêneros. Linguagem em (Dis) curso, ISSN 1518-7632, 2008. Disponível em: <http://www3.unisul.br/paginas/ensino/pos/linguagem/0801/080102.pdf>. Acesso em: 28 jan. 2009.

FERREIRA, Aurélio B. de H. Novo dicionário Aurélio da Língua Portuguesa. Rio de Janeiro: Nova Fronteira, 1986.

MILLER, C. Genre as social action. Quarterly Journal of Speech, n. 70, p. 151-167, 1984.

NOUROUDINE, A. A linguagem: dispositivo revelador da complexidade do trabalho. In: SOUZA-E-SILVA, M. C. P.; FAITTA, D. (Orgs.). Linguagem e trabalho: construção de objetos de análise no Brasil e na França. Tradução de Inês Polegatto e Décio Rocha. São Paulo: Cortez, 2002. p. 17-30.

PALACIOS, Victor Hugo R., VILLACRESES, Xavier Esteban R. Análise do perfil estratégico de empresas de construção civil de pequeno porte. In: FORMOSO, Carlos T. Gestão da qualidade na construção civil: uma abordagem para empresas de pequeno 
porte. Porto Alegre: Programa da Qualidade e Produtividade da Construção Civil no Rio Grande do Sul, 1995. p. 37-48.

ROCHA, D.; DAHER, M. C. F. G.; SANT'ANNA, V. L. A. Produtividade das investigações dos discursos sobre o trabalho. In: SOUZA-E-SILVA, M. C. P.;

FAiTA, D. (Orgs.). Linguagem e trabalho: construção de objetos de análise no Brasil e na França. São Paulo: Cortez, 2002. p. 77-91.

SOUZA-E-SILVA, M. C. P. A dimensão linguageira em situações de trabalho.

In: SOUZA-E-SILVA, M. C. P.; FAiTTA, D. (Orgs.). Linguagem e trabalho: construção de objetos de análise no Brasil e na França. São Paulo: Cortez, 2002. p. 61-76.

TRAVAGLIA, Luiz Carlos. Tipelementos e a construção de uma tipologia geral de textos. In: FÁVERO, Leonor Lopes, et $A L$ (org.). Língua Portuguesa e ensino. São Paulo: Cortez/EDUC, 2003. 


\section{ANEXO}

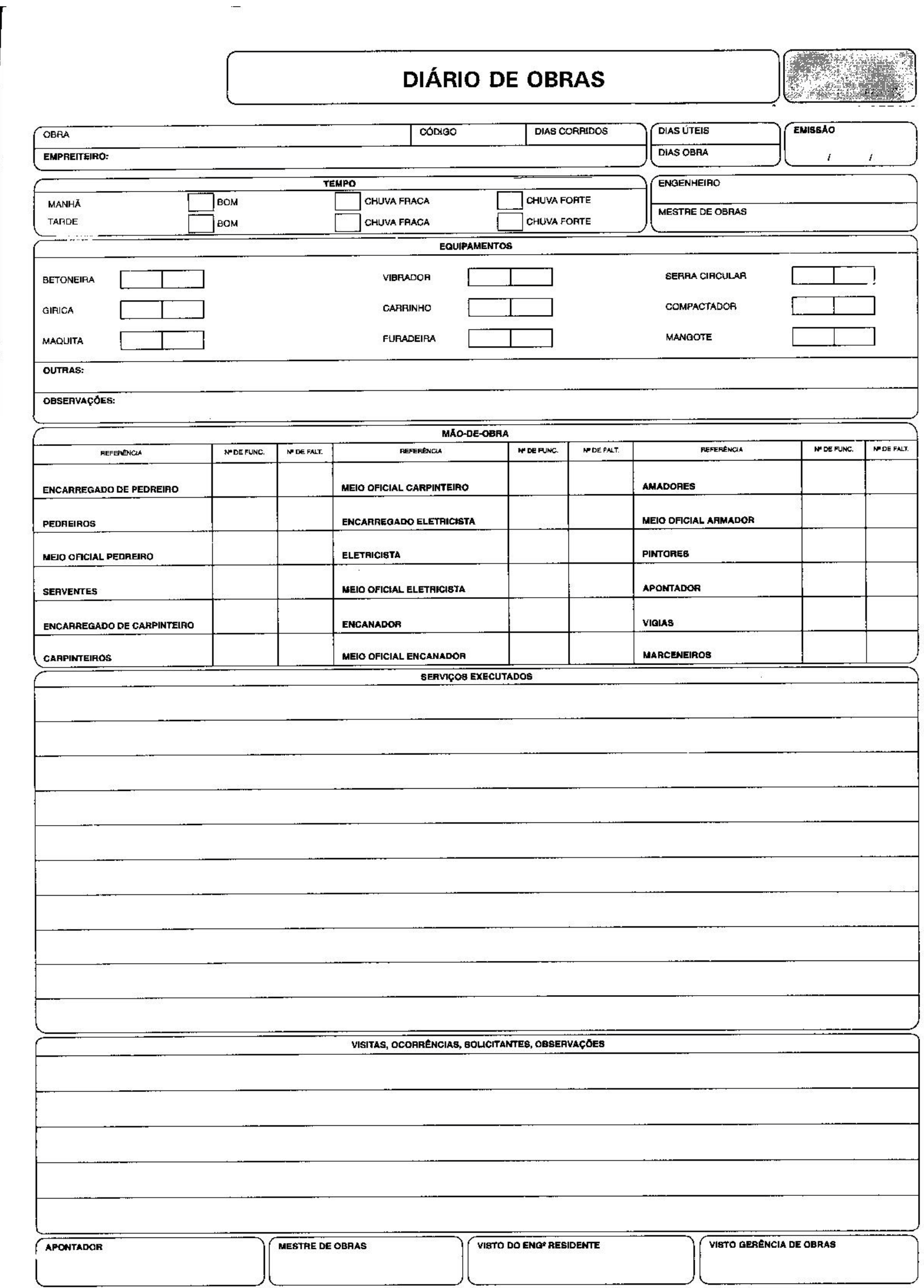

